\title{
The generic pharmaceutical industry: moving beyond incremental innovation towards re-innovation
}

\author{
Fereshteh Barei, PhD; Professor Claude Le Pen, PhD; Professor Steven Simoens, MSc, PhD
}

\begin{abstract}
Background: Due to the declining innovativeness of the classic R \& D model in the original pharmaceutical industry, the generic pharmaceutical industry is aiming to become an innovation generator itself.

Objective: The objective of this article is to gain insight into the re-innovation model in some of the innovative generic pharmaceutical firms. To this effect, we show how some of the generic pharmaceutical firms attempt to achieve competitive advantages either by improving existing product attributes or by replacing new components, reshaping their configuration, and using new technology platforms to produce new innovative products.

Methods: We used a qualitative method to examine re-innovation at several levels within these companies, in their management systems, business models and product portfolios. The research was conducted by a series of semi-structured interviews with chief executive officers, consultants, researchers, patent attorneys, pharmacists and medics in different countries.

Results: Those generic pharmaceutical firms that implement new competitive strategies have integrated re-innovation design into their product portfolio to provide more personalized, cost-effective products to meet the healthcare systems', policymakers' and patients' demand for high quality accessible treatments. This re-orientation hopes to better face the changing competition challenges in both mature and developing markets.
\end{abstract}

Conclusion: A new approach to innovativeness together with a value proposition strategy aims to deliver high quality products to patients.

\section{Keywords: Competition strategy, product portfolio, re-innovation, super generics, technology platforms}

\section{Introduction}

Innovation is widely regarded as an instrument to create competitive advantage. Different types of innovation exist, including incremental innovation, re-innovation and radical innovation. Incremental innovation deals with creating minor improvements or simple adjustments in a product's current state $[1,2]$. Re-innovation has been defined as: 'the process of innovation and product development that occurs after a new product is launched, building upon early success but improving the next generation with revised and refined features' [3]. Finally, radical innovation refers to radical, new inventions that produce milestones, new products or services, and as a result lead to the development of new industries [4]. Today there is less radical product innovation in the original pharmaceutical industry. Moreover, the concept of 'new product' has also evolved by the application of strategies such as incremental innovation and re-innovation. In the past, radical or disruptive innovation changed the pharmaceutical market, whereas today generic pharmaceutical firms attempt to innovate in a less costly way in a shorter time with less regulatory obstacles due to the substantial $\mathrm{R} \& \mathrm{D}$ costs to achieve a radical new product. Incremental innovation and re-innovation meet these objectives.

The generic pharmaceutical industry is now evolving in an innovative way. Some firms are applying strategic changes in their management systems and business models and creating new product portfolios fortified with 'super generics', new chemical entities and novel drug delivery systems. A super generic drug is an improved version of an original drug which has lost product patent protection. The product patent for the original drug will have expired or have been circumvented by the company developing the super generics. The nature of the improvement may include drug delivery, manufacturing or reformulation technology. This kind of value-added version is manufactured in a re-innovation framework. This innovative design is between incremental and radical innovation. Companies producing super generics have a greater regulatory risk in gaining marketing approval compared to strict generics manufacturers [5]. Without getting into the details, there are three regulatory pathways for drug approval in Europe and the US.

The US Food and Drug Administration (FDA) does not recognize the term 'super generics'. These products are also referred to as 'added value generics, new therapeutic entities or hybrids' These products differ from the original product in formulation or method of delivery. These products are improved formulation of a known product.

This group of generics needs a completely New Drug Application (NDA) in order to gain FDA approval. The regulatory pathway in Europe appears to be very similar to that in the US and was introduced within the Directive 2001/83/EC in November 2001 and in the Regulation (EC) No 726/2004. These products are not interchangeable with the brand-name drugs. Those regulatory pathways are summarized in Table 1 .

With a NDA, innovative drug therapies are reaching the market in a specific dosage form for one or more clinically proven indications of which, after expiration of the patent or

Author for correspondence: Fereshteh Barei, PhD, LEGOS - Laboratory of Economics and Management of Health Organizations, Paris Dauphine University, Place du Maréchal de Lattre de Tassigny, FR-75775 Paris Cedex 16, France

Submitted: 17 December 2012; Revised: 4 February 2013; Accepted: 11 March 2013; Published online first: 15 March 2013 


\section{Table 1: Summary of regulatory pathways [7]}

\begin{tabular}{|l|l|l|l|}
\hline & $\mathbf{5 0 5}(\mathbf{b})(\mathbf{1})$ & $\mathbf{5 0 5}(\mathbf{b})(\mathbf{2})$ & $\mathbf{5 0 5}(\mathbf{J})$ \\
\cline { 2 - 4 } & NDA & NDA & ANDA \\
\hline Scientific studies & Full & Partial & BE \\
\hline New active moiety & Yes & Yes & No \\
\hline New indication & Yes & Yes & No \\
\hline New dosage form & Yes & Yes & Limited \\
\hline New strength & Yes & Yes & No \\
\hline Patent & Yes & Yes & No \\
\hline Market exclusivity & Yes & Yes & No \\
\hline BE: bioequivalence; NDA: new drug application; ANDA: abbreviated new drug application. \\
\hline
\end{tabular}

the data exclusivity, copies are launched using Abbreviated New Drug Applications (ANDA). Advanced therapies that emerged from launched molecules during their product life cycle have gained considerable attention as clinical practice provides evidence for additional therapeutic values; patient centric delivery systems show improved therapeutic outcomes or emerging technologies offer efficiency gains in manufacturing or access to emerging markets. The US and European regulatory framework has set reasonable regulations in place for these super generics or hybrid applications. While these regulations are relatively recent the pharmaceutical industry is just starting to use this route for its product development [6, 7].

However, super generics take an average of three to four years development time to registration, and enjoy reduced development and regulatory risks compared to new chemical entities. The end product may gain a significant price premium to conventional generics once marketing approval is received. Depending on the type of modification to the original formulation and whether the super generic drug is being developed for the same or a different indication will also have an impact on the level of additional research that is needed to gain approval for the reformulated product [8]. The quantity of issued patents highlights the technical knowledge and skill sets that are available in generic pharmaceutical firms. The success of these pharmaceutical firms has illustrated the possibility of changing from the classic model of 'copy maker' towards a model of creating new value-added products, manufacturing strategies and new business models [9, 10].

Meanwhile, the demand side for pharmaceutical treatments has also evolved. 'New' customers have emerged, i.e. a better informed, web data empowered generation of patients searching for cost-effective treatments. The generic pharmaceutical industry is reacting to this by applying new business models.

By applying a patient-centred and quality-based perspective into their business models, the generic pharmaceutical industry is attempting to offer new less risky and cost-effective products. The most important aspect is that innovation is no longer just about the product itself, it is also centred on how a company contributes to improving the health of patients. This process has required the outlicensing of innovative generic drug products and has also involved the establishment of new partnerships and alliances to better utilize technological platforms and manufacturing facilities [11]. As an example, Teva Pharmaceuticals acquired Ivax in 2006, Barr Laboratories in 2008, and Ratiopharm in 2010 .

The aim of this article is to gain insight into re-innovation in the generic pharmaceutical industry by focusing on product innovation, and a business model based on value proposition employed by some of the innovative generic pharmaceutical firms. This is an alternative model between hybrid and classic R \& D companies.

\section{Methods}

This research complies with the procedure of Paris Dauphine University not to require consent from an institutional review board when subjects cannot be identified. Also, there are no personal identifiers in the data files or in the results.

We applied a qualitative approach. Semi-structured interviews [12] were conducted because they offer the opportunity to ask experts about their views and experiences of the recent changes. In the absence of studies and documentation on this topic due to its novelty, we conducted interviews with managers, industry consultants, lawyers, physicians, pharmacists, patent attorneys, and researchers to gather more views and share their experiences in this area. We prepared two questionnaires; the original questionnaire was more focused on the intellectual aspect of innovation, trying to investigate about the type of innovation in this industry. In Table 2 we have presented a list of our sources in this qualitative research.

\begin{tabular}{|c|c|}
\hline Methodology & Description \\
\hline Interviews & $\begin{array}{l}27 \text { semi-structured interviews with } \\
\text { consultants, IP and patent attorneys, } \\
\text { marketing directors, formulation } \\
\text { scientists, process experts, health policy } \\
\text { authorities, university researchers, } \\
\text { managers and businessmen }\end{array}$ \\
\hline Survey & Designed according to questionnaire \\
\hline $\begin{array}{l}\text { Observations and } \\
\text { investigations during } \\
\text { the conferences, } \\
\text { forums and work- } \\
\text { shops related to our } \\
\text { subject }\end{array}$ & $\begin{array}{l}\text { First forum on super generics, Budapest, } \\
\text { Hungary, May 2011; Frankfurt World } \\
\text { Pharmaceutical Fair, October 2011; } \\
\text { Conference at University of Cergy- } \\
\text { Pontoise, Department of Law, France, } \\
\text { October 2011; Second Conference of } \\
\text { NexGen about super generics strategies, } \\
\text { Mumbai, India, June 2011; Forthcoming } \\
\text { workshop about super generics in } \\
\text { London, UK, February } 2013\end{array}$ \\
\hline Weblinks & LinkedIn, groups related to our subject \\
\hline $\begin{array}{l}\text { Document analysis/ } \\
\text { literature review }\end{array}$ & $\begin{array}{l}\text { Articles, books, reviews, reports, } \\
\text { presentations }\end{array}$ \\
\hline
\end{tabular}


The questionnaire had three parts: the first part was about innovation strategy and how it has influenced the generic drug form; the second part was about innovation in their business model, and how do they boost their model by value proposition to customers; the third part was about innovation in the product portfolio and the reasons of product selection and the use of new technology platforms and new statistical methods to reduce risks and optimize product manufacturing in a shorter time to a quicker access to market. We checked the questions with two researchers who were specialists in survey design and we consulted with an American economist who conducts this type of research in order to validate our questionnaire, some of the questions were added during or after some interviews.

Some new topics emerged during the interviews. From April to October of 2011, a total of 20 interviews were conducted in Basel, Budapest, Paris, at the forum on 'Biopharmaceuticals and Supergenerics', and in Frankfurt. There are also some interviews that were conducted by telephone calls to Australia, India, UK and US.

We have also followed relevant forums and conferences in France, Hungary, and International Fairs like the CPhI Worldwide in Frankfurt, Germany, to get up-to-date information.

During the first forum on super generics in Budapest, Hungary, we discussed the regulatory aspect of this innovation in the companies manufacturing innovative products known as super generics, hybrid products and value added generics. In Frankfurt, we met for the first time the specialists we contacted via LinkedIn and by email. It was a unique occasion to meet and discuss with the representatives of the super generics manufacturers worldwide.

We studied almost every day every piece of news related directly or indirectly to our research coming from reliable references. This shows that quality by design (QbD) is a very important concept and that innovative generic drug firms may apply QbD not only to reduce the risk of product failure but also to respond to the demands of FDA.

Several economic and financial reports from Business Insight, Data Monitor, IMS, Ernest \& Young, Markets and Research were also reviewed before and during the interviews. The companies that accepted participation in this research are: Mayne Pharma (Australia), Capsugel (Belgium), Biogaran (France), Gedeon Richter (Hungary), Dr Reddy (India) and Hanmi (Korea). The other participants were from drug development companies, consultancy companies, and formulation scientists. Other information was collected using the websites of the associations of generic drugs, such as the European Generic medicines Association (EGA); the generic drug industry association in France (GEMME, Association des professionnels du médicament générique); the American Generic Pharmaceutical Association (GPhA); and the International Generic Pharmaceutical Alliance (IGPA) as part of their insights into 2010 on the generics markets in Europe.

\section{Data analysis}

We have constructed a database of our data collected from the interviews. Interviews were recorded, transcribed verbatim and analyzed using the software NVivo 9.2 software according to the Matrix Framework approach. We used NVivo Dataset and survey to explore our findings. In practice we began by coding the 'raw' data at nodes representing themes in our text-data. Alternatively, we ran 'Text' search query or 'Word' frequency to identify common themes in survey responses before coding them. Matrix coding analysis helped us to associate the main results to the three main axes of our research work: Innovation in management system, Business model innovation and Product portfolio innovation. Framework matrices provided a way to summarize or condense the source materials in a grid. Subsequently, we launched questions and found patterns based on our coding and checked for coding consistency among interviewees. This method helped us to compare results, and to identify new perspectives of the survey results that could not be acquired without running the queries and coding the results.

\section{Results}

Producing novel products is defined as the part of new product development strategy which explores the extension of existing innovations, which can only happen after the first generation of a new product is launched [13]. This is, for example, the case with the development of super generics and bio-superior products that follow on from reference biopharmaceutical products. Being built upon early successful products, re-innovative products are created through applying new platforms, new components, or new configurations with breakthrough technologies to previous products or manufacturing processes [14, 15]. The new re-innovated medicines are focusing on improving health outcomes for patients.

'.. In the past, successful pharmaceuticals stemmed from having good clinical trial data which companies owned and controlled. In the future, their success in the market will instead be evaluated by post marketing data resulting from patients' satisfaction, of which they will no longer have sole possession ...' (Pharma Researcher, UK)

At the industrial level, through re-innovation attempts, generic pharmaceutical firms aim to minimize the new product failure rate [7], reduce the cost of developing a new product and decrease the lead time in bringing it to market. A pharmaceutical product developed and manufactured with less excipients and unit operation, while maintaining the product therapeutic performance compared to the originator, could be considered as an improved therapeutic entity as it reduces the overall costs of manufacturing that could lead to reduced healthcare spending [16].

Innovative generic pharmaceutical firms may apply QbD and design of experiment methods to optimize their production outcome and minimize the risk. Quality by design means designing and developing a product and associated manufacturing processes that will be used during product development to ensure that the product consistently attains a predefined quality at the end of the manufacturing process [17]. Statistical methods are becoming increasingly vital for pharmaceutical firms. Design of experiments is a tool for determining the relationship between the factors that have an effect on a process and the response of that process [18]. 
The re-innovative product (as compared to an incremental new product) can be defined as a product that provides new features, benefits, or improvements through existing technology. As such, re-innovation and incremental innovation are different in two aspects: 1) incremental products are improved only by incremental technologies while breakthrough technologies can be used in re-innovative products; and 2) incremental products must be based on the current platform but re-innovative products are either (mostly) based on a new platform or (occasionally) based on an existing platform [19].

‘... As to technology platforms, if for example you consider aerosolization as a platform, then using such a platform to create new, better forms of an existing entity are part of re-innovation ...' (US Manager, 2012)

Re-innovation by the generic pharmaceutical industry can be observed in drug product design, formulation, process development and manufacturing processes going back to the early stages of the product development cycle.

Some product examples are:

1-Abraxane, super generic form of Taxol (FDA, 2005), which uses albumin to deliver the chemotherapy, not Cremophor, and so avoids hypersensitivity and claims a greater tumour response rate than Taxol. The drug Abraxane (nanoparticle albumin bound paclitaxel) uses the approach of coating Taxol with albumin to reduce the side effects associated with standard Taxol (paclitaxel), making it possible to give it without steroids (which can be a rather bothersome issue for many patients, causing problems from severe insomnia to very high blood sugars and more) and also reducing some other Taxol-associated side effects like joint and muscle aches [20, 21].

2-SUBACAP is an improved version of the conventional itraconazole formulation used to treat fungal infections. In June 2012, Mayne Pharma announced that the UK Medicines and Healthcare products Regulatory Agency (MHRA) had reversed its previous decision on SUBACAP and advised that the SUBACAP marketing authorization application was approvable in the UK. Mayne Pharma is in the process of submitting the response to re-activate the 'Decentralized Procedure' to seek approval in Germany, Spain and Sweden. Following approval in these countries, the company will seek a second round of approvals in other European countries, including Belgium, Italy, Greece, Portugal and The Netherlands. The total European market sales of itraconazole in 2011 were US $\$ 85$ million (companies communication and annual report 2012). SUBACAP provides enhancements to patients and prescribers with reduced inter- and intra-patient variability and therefore a more predictable clinical response enabling a reduction in active drug quantity to deliver therapeutic blood levels. Itraconazole is one of the broadest spectrum antifungal drugs on the market and can be used to treat both superficial fungal infections such as onychomycosis (nail infection) and systemic fungal infections such as histoplasmosis, aspergillosis and candidiasis which can be life threatening to immunocompromised patients [22].
Another example of novel technology platform used in super generic drug manufacturing is the application of nanoparticle technology to address challenges associated with the delivery of poorly soluble compounds. Re-innovation has, for example, led to the development of a tablet dosage form that incorporated candesartan cilexetil nanoparticles [23-28] to reduce dosage, reduce toxicity, improve bioavailability and enhance solubility. The original candesartan cilexetil is used for the treatment of hypertension. The major drawback in the therapeutic efficacy of candesartan cilexetil is its very low aqueous solubility leading to low and variable bioavailability. Low bioavailability may lead to variability in therapeutic response. The formulation change resulting from Design of Experiments and nanoparticle technology resulted in better solubility. Using Design of Experiments for process optimization resulted in a robust scalable manufacturing process with design space established for critical process parameters that can balance milling time, particles size and yield. Design of Experiments studies indicated that, out of the three parameters tested in the experimental design, disc speed, pump speed and bead volume were found to affect the critical product attributes either through non-linear, quadratic or interaction effects [29, 30].

The robustness of the model was validated based on confirmatory trials that indicated statistically no difference between predicted and experimental values. The rate and extent of drug dissolution from tablet dosage form incorporating drug nanoparticles was significantly higher than in the tablet containing micronized drug and marketed product.

The increase in drug dissolution resulted in significant enhancement in rate $\left(\mathrm{C}_{\max }\right)$ and extent of drug absorption (AUC).

The manufacturing process used is simple and scalable indicating general applicability of the approach to develop oral dosage forms of sparingly soluble drug.

The formulation approach used provides a viable approach to enhance dissolution and bioavailability of sparingly soluble compounds (BCS class II) that may translate into improved therapeutic outcome [23].

This innovative change is also illustrated by the following quote:

'Super-generic [drug] products, mostly nano- and micro-sized drug delivery systems, focus on improving active principles which were previously commercialized in another formulation. These new formulations are certainly not bioequivalent in the generic [drug] industry's sense of the term, they are therefore not generics. They are new, i.e. innovative, drugs, which can replace treatment with the previous entity.' (Drug Delivery Manager, USA)

Another example of re-innovation in super generic drugs relates to the development of a per oral [29] dosage form for a sparingly soluble camptothecin analogue. This was achieved by formulating it as a drug complex [30]. This formulation approach addressed limitations of the currently marketed product that is only amenable for intravenous administration. The drug complex following oral administration demonstrated safety and 
efficacy comparable to marketed product in athymic mice with implanted tumours. The manufacturing process used is simple and scalable indicating general applicability of the approach to develop oral dosage forms of sparingly soluble drugs. An oral dosage form should result in lower treatment cost, better patient compliance and improved therapeutic outcome for better disease management [23].

In a recent compliance review for antihypertensive drug treatments it was found that some drug classes have significantly poorer adherence performance by patients than other drug classes. Only one third of patients were adherent to $\beta$-blockers and diuretics, while two thirds of patients were adherent to angiotension converting enzyme inhibitors and angiotensin II Receptor blockers [31]. Even an adherence of two-thirds of patients still remains at an unsatisfactory low level and leaves considerable room for improvement.

Modifying the release of drugs that have a short biological halflife by extending their release, circumvents high plasma peaks, reduces fluctuations in plasma levels and allows for a once-daily intake that can optimize therapy. This can avoid the daily oral intake for people with dysphagia or dementia. In this new business model, therapy is moving away from a clinical parameter oriented treatment to an outcome oriented disease management programme [32].

\section{Discussion}

The low price of generic drugs threatens to undermine the sustainability of the generic pharmaceutical industry in regards to its low margins, number of competitors, increased requirements for pharmacovigilance, the mature markets in developed countries, and the post-patent cliff arena after 2015 [8]. Meanwhile, medical and technological changes push the pharmaceutical industry to implement new business models. These changes coincide with a growing demand from ageing populations, and better-informed patients who have a substantial need for individualized cost-effective treatments.

Several generic pharmaceutical firms have evolved their traditional business models into innovative models. These models are key to maintaining market position. They are focused on patients' unmet medical needs and a high quality approach to the manufacturing process.

The innovative business models emerge from new management systems. The challenge of new management systems in these innovative generic pharmaceutical firms is on product innovation: how to manage a better organization to achieve a maximum product differentiation through value proposition to patients? How to optimize product quality? How to reduce manufacturing costs? How to reduce the time to market?

The generic pharmaceutical industry is evolving into a less generic, but more innovative format. In this respect, it should be noted that many generic pharmaceutical firms have the capacity to re-innovate. They have experience, good knowledge and the technical possibility to re-innovate. Alternatively, new alliances can provide the necessary financial resources for technical and marketing requirements.
Implementing re-innovation as a strategy strives to convert price-focused competition into product quality competition, this is central to an innovative business model. Some generic pharmaceutical firms are re-innovating their product portfolio by using new technology platforms, new components and new configurations. These attempts have mainly resulted in super generic drugs; value added products or hybrid products and biosimilars. These super generic drugs and improved therapeutic entities are an important source for innovation in drug therapy in the coming decades.

The so-called super generics are a promising alternative. The value added products resulting from re-innovation strategy by using new 'technology platforms', new components and new services will be a strategic element for affordable and individualized medicines.

According to our findings:

1. The classic innovation model of R \& D in Big Pharma is no longer able to provide sufficient results, because it is too costly, too time-consuming and too risky. There are more regulatory barriers, changing demographic and economic features, and Big Pharma is becoming too big to manage innovation. Generic pharmaceutical company aims to provide innovative products to meet: price pressure, low margins, government's pressure, competition, mature markets, and tendering.

2. The generic pharmaceutical industry is facing now unmet medical needs of a new generation of patients (demandside is evolved), there is a real demand for high quality geriatric pharmaceuticals for a rapidly ageing population in some developed countries such as Japan.

3. Better results will be obtained by using novel technology platforms to achieve new formulations, reducing costs and time by applying QbD.

4. These new products produced by some generics companies are only one example; they try to switch to biosimilars, and new chemical entities. The future is related to a new kind of disease management requiring more value for more affordable treatments.

This research may be followed by further investigation in innovative business models adapted by an evolving generic pharmaceutical industry that has not yet been studied. A quantitative study of $\mathrm{R} \& \mathrm{D}$ investment and strategic alliances in an innovative generic pharmaceutical industry will reveal more.

\section{Conclusion}

Due to evolution in the pharmaceutical industry landscape, some generic pharmaceutical companies are restructuring their business models. In this new industrial design, some of the generics manufactures are re-inventing their product portfolio through a re-innovation strategy. New technology platforms, new components and new configurations are adopted to provide patient compliance and increase patient quality of life. Super generics, biosimilars, bio-superiors and value added versions are some of the new product alternatives resulting from this innovative evolution. The product itself is not the only target; the conversion of competition from price to product quality ensures 
the value proposition and provides product differentiation New innovative product portfolios are the evidence that innovative generics companies are not only mastering incremental innovation but are also adopting re-innovation in their new strategies. In this perspective, biotechnology, nanosciences and nanotechnology are 'strategic' areas for its scientific and commercial development.

\section{For patients}

For patients, the innovative changes in product portfolios struggle to improve patient's quality of life, reduce side effects and enhance efficiency by new product alternatives. These new product alternatives are developed by applying new technology platforms like nanotechnology. Enhancing drug solubility is often key to improving a product's formulation. New nanotechnologies $^{\mathrm{a}}$ are now being used to solubilize drugs with the aim of improving bioavailability and activity, and reducing in vivo variability $^{\mathrm{b}}$.

The re-innovated product portfolios propose more personalized products according to patient's unmet medical needs. Non-compliance can be attributed to poor taste, difficulty in administration or swallowing, and the inconvenience of multiple doses per day. Non-compliance is a frequent issue (see Cap Gemini Ernest \& Young, Compliance Discovery Workshop, 2003). General reasons for non-compliance include: side effects/adverse events, lack of access, financial constraints and lack of communication or information, poor taste and difficulty to swallow (inconvenience in administration). Compliance is dependent on the class of drugs. Some of the new super generics have the advantage of a lower dose, they have the same positive effect provided by the original version, and have significantly reduced adverse side effects [33]. The importance of the oral route of administration [34] from both a clinician and patient acceptance point of view means there has been a vast amount of development and research in drug delivery via this route. Pharmaceutical devices will continue to drive patient compliance and acceptability. The convergence of microelectromechanical systems and nanotechnology with biological applications offers breakthrough in drug developments [35]. As such, improved therapeutic entities could bring innovation faster and at lower risk to society and help to improve health outcomes [36].

For further reading, please refer to references 37 to 47 .

Competing interests: Professor Claude Le Pen is professor of health economics at Paris Dauphine University. He has also several organizational, scientific and governmental

\footnotetext{
${ }^{a}$ Nanotechnology is the science of manipulating materials on a scale so small that they cannot be seen with a regular microscope. The technology could have a broad range of applications, such as increasing the effectiveness of a particular drug, improving the packaging of food, or altering the look and feel of a cosmetic. Nanotechnology could also be used in medicines designed for the detection, treatment, and prevention of disease; food production and preservation; water decontamination and purification; environmental remediation; lighter and stronger materials for construction and transportation; and energy resources such as solar cells and fuel-efficiency additives, just to name a few. Paul C Howard, PhD, Director of the Office of Scientific Coordination and Director of the Nanotechnology Core Facility at FDA's National Center for Toxicological Research, FDA website, 2011

'Skyepharma and Elan have developed technologies that have been used to reposition wellknown drugs (fenofibrate, megestrol and sirolimus).
}

responsibilities. Professor Steven Simoens holds the EGA Chair 'European policy towards generic medicines'. The authors have no conflicts of interest that are directly relevant to the content of this manuscript. This research received no specific grant from any funding agency in the public, commercial, or not-forprofit sectors.

Provenance and peer review: Not commissioned; externally peer reviewed.

\section{Co-authors}

Professor Claude Le Pen, PhD

LEGOS, Laboratory of Economics and Management of Health Organizations, Paris Dauphine University, Place du Maréchal de Lattre de Tassigny, FR-75775 Paris Cedex 16, France

Professor Steven Simoens, MSc, PhD

Department of Pharmaceutical and Pharmacological Sciences, Research Centre for Pharmaceutical Care and Pharmacoeconomics, Katholieke Universiteit Leuven, Onderwijs en Navorsing 2, PO Box 521, 49 Herestraat, BE-3000 Leuven, Belgium

\section{References}

1. Banbury C, Mitchell W. The effect of introducing important incremental innovations on market share and business survival. Strategic Management Journal. Special Issue. 1995;16 S1:161-82. doi:10.1002/smj.4250160922

2. Henderson RM, Clark KB. Architectural innovation: the reconfiguration of existing product technologies and the failure of established firms. Adminstrative Science Quarterly. 1990;35(1):9-30.

3. Rothwell R, Gardiner P. The strategic management of re-innovation. R \& D Management. 1989;19(2):147-60.

4. Cheng C, Shiu E. Preconditions for product innovation in Taiwan: evidence from high technology firms, Asia Pacific Business Review. 2008;14(2):191-211.

5. Parrek A. A cost effective clinical trial procedures to ensure the smooth development and approval of super generics. 2nd Annual NextGen 2011: Supergenerics Strategies. 27-29 April 2011, Mumbai, India. Data on file.

6. Nadler HL, Degraft-Johnson D. Demystifying FDA's 505(b)(2), drug registration process. Regulatory Affairs Professionals Society (RAPS); 2009.

7. Stegemann S, Klebovich I, Anta I, et al. Improved therapeutic entities derived from known generics as an unexplored source of innovative drug products. Eur J Pharm Sci. 2011;44(4):447-54. doi:10.1016/j.ejps.2011.09.012

8. Buggle I. Marketing opportunities for supergenerics. Business Insight. 2010; 38-46. Data on file.

9. Sommerfeld T. Strategic options for mid-sized generic players. Journal of Generic Medicines. 2005;2(4):308-15.

10. Kermani F. Generic companies: aspiring to innovate. Journal of Generic Medicines. 2004;1(4):336-46.

11. The significance and apparent repercussions of 2009-2015 pharmaceutical patent cliff. Bioassociate. Innovative Consulting; 2012.

12. Pope C, Mays N. Qualitative research in health care. 3rd ed. Blackwell Publishing: Oxford; 2008. p. 22-43.

13. Cheng C, Shiu E. Re-innovation - what is it and what could influence its performance? Academy of Marketing Conference; 2006: London, UK. Conference Paper No. 254.

14. Rothwell R, Gardiner P. Invention, innovation, re-innovation and the role of the user: A case study of the British Hovercraft development. Technovation. 1985;3(3):167-86.

15. Rothwell R, Gardiner P. Re-innovation and robust designs: producer and user benefits. Journal of Marketing Management. 1988;3(3):372-87 
16. Yu LX. Pharmaceutical quality by design: product and process development, understanding, and control. Pharm Res. 2008;25(4):781-91.

17. Anderson MJ, Whitcomb P. Design of experiments. In: Kirk-Othmer Encyclopedia of Chemical Technology. Wiley; 2010. p. 1-22.

18. Dosage forms and routes of administration [homepage on the Internet]. [cited $2013 \mathrm{Feb} 4$ 4]. Available from: scribd.com/doc/22880389/Dosage-Forms-andRoutes-of-Administration

19. Nekkanti V, Karatgi P, Paruchuri S, et al. Drug product development and pharmacological evaluation of a sparingly soluble novel camptothecin analog for peroral administration. Drug Delivery. 2011;18(4): 294-303.

20. Drug delivery innovations driving improved patient compliance [homepage on the Internet]. C2011 [cited 2013 Feb 4]. Available from: http://www.marketresearch.com/product/display.asp?ProductID $=6481767$

21. Abraxane bests taxol in response rate for nsclc: what might this mean? [homepage on the Internet]. 2010 [cited 2013 Feb 4]. Available from: http:/ cancergrace.org/lung/2010/03/20/prelim-abraxane-vs-taxol-rr-results/

22. Mayne Pharma reports final FY12 result. Melbourne, Australia: Australian Securities Exchange. 2012 Aug 21 [cited 2013 Feb 4]. Available from: http:// www.asx.com.au/asxpdf/20120821/pdf/4284tjk7gfxtsc.pdf

23. New formulation technologies to fast track development of super generics. Pillai R. Dr Reddy's Laboratories, 2011. Data on file.

24. Basa S, Muniyappan T, Karatgi P, Prabhu R, Pillai R. Production and in vitro characterization of solid dosage form incorporating drug nanoparticles. Drug Dev Ind Pharm. 2008;34(11):1209-18.

25. Nekkanti V, Karatgi P, Joshi M, Pillai R. Developing nanoparticle formulations of poorly soluble drugs. Pharm Tech Europe. 2008 Nov;20(11):24.

26. Nekkanti V, Pillai R, Venkateswarlu V, Harisudhan T. Development and characterization of solid oral dosage form incorporating candesartan nanoparticles. Pharm Dev Technol. 2009;14(3):290-8.

27. Singare DS, Marella S, Gowthamrajan K, Kulkarani GT, Vooturi R, Srinivasa P, Rao PS. Optimization of formulation and process variable of nanosuspension: an industrial perspective. Int J Pharm. 2010;402(1-2):213-20.

28. Nekkanti V, Venkateswarlu V, Ansari KA, Pillai R. Development and pharmacological evaluation of a PEG based nanoparticulate camptothecin analog for oral administration. Curr Drug Deliv. 2011 Nov;8(6):661-6.

29. Nekkanti V, Muniyappan T, Karatgi P, Hari MS, Marella S, Pillai R. Spray-drying process optimization for manufacture of drug-cyclodextrin complex powder using design of experiments. Drug Dev Ind Pharm. 2009; 35(10):1219-29.

30. Nekkanti V, Karatgi P, Paruchuri S, Pillai R. Drug product development and pharmacological evaluation of a sparingly soluble camptothecin analog for peroral administration. Drug Deliv. 2011 May;18(4):294-303.

31. Kronish IM, Woodward M, Sergie Z, Ogedegbe G, Falzon L, Mann DM. Metaanalysis: impact of drug class on adherence to antihypertensives. Circulation. 2011;123(15):1611-21
32. Stegemann et al. Improved therapeutic entities derived from known generics as an unexplored source of innovative drug products. Eur J Pharm Sci. 2011;44:447-54.

33. Cuba develops its first industrial-scale nanopharmaceutical. Latin American Herald Tribune. 2013 Feb 12. Available from: http://www.laht.com/article.as p?ArticleId $=587208 \&$ CategoryId $=14510$

34. Pareek A. Leveraging innovation in generics: a business imperative for pharmaceutical companies. First conference on Supergeneric innovation 2010; Mumbai, India.

35. Ross MS. Innovation strategies for generic drug companies: moving into supergenerics. IDrugs. 2010 Apr;13(4):243-7.

36. Gassmann $\mathrm{O}$, Reepmeyer $\mathrm{G}$, Zedtwitz M. Leading pharmaceutical innovation. 2nd ed. Berlin: Springer Verlag; 2004. Chapter 2: Pharmaceutical innovation: the case of Switzerland, p. 23-52, chapter 3: The science and technology challenges, how to find new drugs? P. 53-77.

37. Kale D. Learning to innovate: the Indian pharmaceutical industry response to emerging TRIPs regime. DRUID Academy Winter 2005 PhD Conference; 2005: Aalborg, Denmark.

38. Simoens S, De Coster S. Sustaining generic medicines markets in Europe. Journal of Generic Medicines. 2006;3(4):257-68.

39. Le Pen C. Consommation pharmaceutique et indicateurs de santé publique. Leem. 2009.

40. Ring in generics in 2012 and beyond. Zacks Equity Research - 2011 Dec 29 [cited 2013 Feb 4]. Available from: http://www.zacks.com/stock/news/67042/ Ring + in + Generics+in+2012+and+Beyond

41. Dingermann T. Innovator companies should focus on innovations. Generics and Biosimilars Initiative Journal (GaBI Journal). 2012;1(1):6. doi:10.5639/ gabij.2012.0101.003

42. Class JN, Langis 1. A patient-centred paradigm for the biosimilar market? Generics and Biosimilars Initiative Journal (GaBI Journal). 2012;1(1):17-21. doi:10.5639/gabij.2012.0101.006

43. Van Lerberghe W. The world health report 2008. Primary health care [homepage on the Internet]. 2013 [cited 2013 Feb 4]. Available from: http:// www.who.int/whr/2008/en

44. Shaw B. The role of the interaction between the user and the manufacturer in medical equipment innovation. R \& D Management. 1985;15(4):283-92.

45. Terziovski M. Building innovation capability in organizations: an international cross-case perspective. Imperial College Press, London; 2007. p. 157-75.

46. Cheng CJ, Shiu E. Re-innovation: the construct, measurement, and validation. Technovation. 2008;28(10):658-66.

47. Miele E, Spinelli GP, Miele E, Tomao F, Tomao S. Albuminbound formulation of paclitaxel (Abraxane ABI-007) in the treatment of cancer. Int J Nanomedicine. 2009; 4:99-105.

DOI: 10.5639/gabij.2013.0201.011

Copyright $\odot 2013$ Pro Pharma Communications International 